\title{
Italian and Swedish adolescents: Differences and associations in subjective well-being and psychological well-being
}

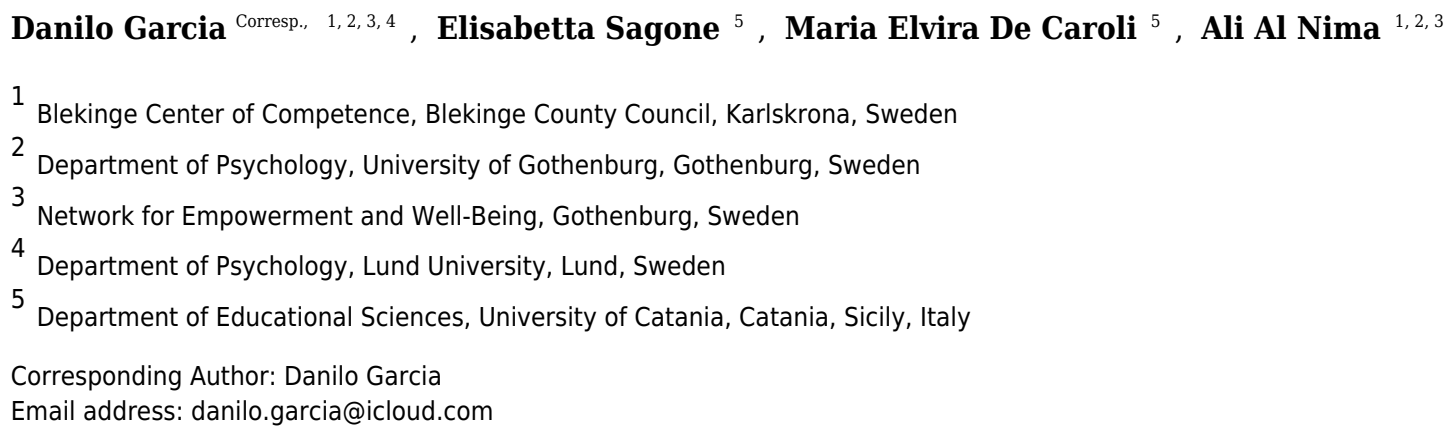

Background: One important aspect of subjective judgments about one's well-being (i.e., subjective wellbeing: life satisfaction, positive affect, and negative affect) is that cultural features, such as, nationality seem to shape cognitive judgments about the "the ideal life". In this comparative study we examined differences in subjective well-being and psychological well-being between Italian and Swedish adolescents and tested if the relationship between the three constructs of subjective well-being (i.e., satisfaction with life, positive affect, and negative affect) and psychological well-being was moderated by the adolescents' nationality.

Method: Italian ( $n=255)$ and Swedish $(n=277)$ adolescents answered to the Satisfaction with Life Scale, the Positive Affect Negative Affect Schedule, and Ryff's Scales of Psychological Well-Being. Differences between samples were tested using a Multiple Analysis of Variance. We also conducted a multiple group analysis (Italy and Sweden) using Structural Equation Modelling to investigate the relationship between all three subjective well-being constructs and psychological well-being.

Results: Italian adolescents scored significantly higher in satisfaction with life than Swedish adolescents. Additionally, across countries girls scored significantly higher in negative affect than boys. In both countries all three constructs of subjective well-being were significantly associated to adolescents' psychological well-being. Nevertheless, while the effect of the relationship between affect and psychological well-being was almost the same across countries, life satisfaction was more strongly related to psychological well-being among Swedish adolescents.

Conclusions: The present study shows that there are larger variations between these two cultures in the cognitive construct of subjective well-being than in the affective construct. Accordingly, associations between the cognitive component, not the affective component, of subjective well-being and psychological well-being differ between countries as well. 
1 Submitted to PeerJ

2 Please do not quote without permission

3

4

5

6

7

8

9

10

11

12
Italian and Swedish adolescents:

Differences and Associations in Subjective Well-Being and Psychological Well-Being Danilo Garcia ${ }^{1,2,3,4 *}$, Elisabetta Sagone ${ }^{*}$, Maria Elvira De Caroli ${ }^{5}$, Ali Al Nima ${ }^{1,2,3}$ ${ }^{1}$ Blekinge Centre for Competence, Blekinge County Council, Karlskrona, Sweden ${ }^{2}$ Department of Psychology, University of Gothenburg, Gothenburg, Sweden ${ }^{3}$ Network for Empowerment and Well-Being, Sweden ${ }^{4}$ Department of Psychology, Lund University, Lund, Sweden ${ }^{5}$ Department of Educational Sciences, University of Catania, Catania, Sicily, Italy 


\section{Abstract}

25 Background: One important aspect of subjective judgments about one's well-being (i.e., subjective well-being: life satisfaction, positive affect, and negative affect) is that cultural features, such as, nationality seem to shape cognitive judgments about the "the ideal life". In this comparative study we examined differences in subjective well-being and psychological wellbeing between Italian and Swedish adolescents and tested if the relationship between the three constructs of subjective well-being (i.e., satisfaction with life, positive affect, and negative affect) and psychological well-being was moderated by the adolescents' nationality.

Method: Italian $(n=255)$ and Swedish $(n=277)$ adolescents answered to the Satisfaction with Life Scale, the Positive Affect Negative Affect Schedule, and Ryff's Scales of Psychological Well-Being. Differences between samples were tested using a Multiple Analysis of Variance. We also conducted a multiple group analysis (Italy and Sweden) using Structural Equation Modelling to investigate the relationship between all three subjective well-being constructs and psychological well-being.

Results: Italian adolescents scored significantly higher in satisfaction with life than Swedish adolescents. Additionally, across countries girls scored significantly higher in negative affect than boys. In both countries all three constructs of subjective well-being were significantly associated to adolescents' psychological well-being. Nevertheless, while the effect of the relationship between affect and psychological well-being was almost the same across countries, life satisfaction was more strongly related to psychological well-being among Swedish 46 adolescents.

Conclusions: The present study shows that there are larger variations between these two cultures in the cognitive construct of subjective well-being than in the affective construct. Accordingly, associations between the cognitive component, not the affective component, of subjective wellbeing and psychological well-being differ between countries as well. 


\section{Introduction}

58 Researchers in the field of Positive Psychology (Seligman, 2002) and the Science of Well-Being

59 (Cloninger, 2004; Cloninger \& Garcia, 2015) are interested in protective factors of healthy

60 human development. Among these factors, both subjective well-being and psychological well-

61 being $^{l}$ are considered as interrelated psychological characteristics involved in positive human

62 functioning, such as, resilience and hardiness (Seligman \& Csikszentmihalyi, 2014; Fredrickson,

63 2001; Folkman \& Moskowitz, 2000). Subjective well-being is composed of life satisfaction,

64 positive affect, and negative affect (Diener, 1984). Life satisfaction entails the cognitive part of

65 subjective well-being and is the person's evaluation of her/his life a whole in relation to her/his

66 ideal life (Diener, 1984). Judgments of life satisfaction are influenced by information accessible

67 at the time of the evaluation (see Schimmack, Diener \& Oishi, 2002). Positive affect entails a

68 person's tendency to feel positive states, such as, enthusiastic, active, and alert, while negative

69 affect the tendency to feel distress and unpleasurable engagement, such as, anger, disgust, guilt,

70 and fear (Watson, Clark \& Tellegen, 1988). Swedish adolescents characterized by high levels of

71 positive affect in combination with low levels of negative affect (i.e., a self-fulfilling affective

72 profile) experience high levels of energy, optimism, self-esteem, optimism, internal locus of

73 control, and low levels of stress (Archer, Adrianson, Plancak \& Karlsson, 2007; Archer,

74 Adolfsson \& Karlsson, 2008). More recently, among Italian adolescents, Di Fabio and Bucci

75 (2015) demonstrated that high school students with a self-fulfilling profile scored higher on life

${ }^{1}$ For an interesting debate on whether wellness equals happiness, and suggesting that subjective well-being is the 'Big One' appropriate assessment of both see among others: Biswas-Diener, Kashdan \& King, 2009; Delle Fave and Bassi 2009; Kashdan, Biswas-Diener \& King, 2008; Ryan and Huta 2009; Straume and Vittersø 2012; Waterman 2008. 
76 satisfaction, self-esteem, life meaning, and optimism than students with any other type of

77 affective profile (see Garcia, 2011 for similar results among Swedish adolescents). Thus showing

78 that the affective construct of subjective well-being is associated to similar positive outcomes

79 across Swedish and Italian cultures during adolescence.

80 Psychological well-being is also considered a major factor for optimal human functioning

81 (Ryff \& Keyes, 1995; Ryff \& Singer, 1998), occasionally investigated as a predictor variable or

82 an antecedent of individual positive development, but also as the outcome of high levels of

83 subjective well-being (Ryff, 2013). The elements of psychological well-being are represented by

84 self-acceptance (i.e., acceptance of the self, self-actualization, optimal functioning, and

85 maturity), positive relations with the others (i.e., the ability to express feelings of empathy and

86 affection for all human beings and to be able of greater love and friendship, and identification

87 with others), autonomy (i.e., independence and regulation of behavior through internal locus of

88 control), environmental mastery (i.e., the ability to create environments suitable to healthy

89 conditions), purpose in life (i.e., a sense of goal directedness and intentionality), and, finally,

90 personal growth (i.e., the realization of one's potentialities, underlining the value of new

91 challenges at different moments of one's own life). Psychological well-being has been studied

92 among adolescents in relation to other constructs such as resilience and hardiness Kobasa, Maddi

93 \& Kahn, 1982; Masten, Hubbard, Gest, Tellegen, Garmezy \& Ramirez, 1999; Sagone \& De

94 Caroli, 2014; De Caroli \& Sagone, 2016), adaptive coping strategies and sense of coherence

95 (Pallant \& Lae, 2002), and in relation to subjective well-being operationalized as affective

96 profiles (Garcia \& Siddiqui, 2009ab; Garcia, Nima \& Kjell, 2014).

Among Swedish adolescents and young adults, for example, psychological well-being

98 has been associated to all three constructs of subjective well-being, essentially showing that high 
99 levels of positive affect, low levels of negative affect, and high levels of life satisfaction are

100 strongly related to high levels of psychological well-being (Garcia \& Siddiqui, 2009ab; Garcia \&

101 Archer, 2012; Garcia, Nima \& Kjell, 2014). Accordingly, more recently, among Italian

102 adolescents, it was noted that individuals with the self-fulfilling profile reported higher resilience

103 (in detail, sense of humor, competence, adaptability, and engagement) and psychological well-

104 being (in terms of full autonomy, sense of purpose in life, and self-acceptance) than adolescents

105 with any other type of affective profile (De Caroli \& Sagone, 2016). Furthermore, Italian boys

106 expressed higher levels of psychological well-being than girls, specifically, in environmental

107 mastery and self-acceptance (Sagone \& De Caroli, 2014; See Garcia, 2011 for similar results

108 among Swedish adolescents). In some other studies, psychological well-being has showed

109 significant correlations to other measures of well-being, such as, sense of vitality (Ryan \&

110 Frederick, 1997) and optimism (Scheier, Carver \& Bridges, 2001).

111 One important aspect of the subjective well-being constructs (i.e., life satisfaction,

112 positive affect, and negative affect) is that cultural features, such as, nationality, ethnicity,

113 religious affiliation, and motivation seem to shape how individuals understand "the ideal life"

114 (Tsai, Knutson, and Fung, 2006; Tsai, Miao, and Seppala, 2007; Scollon, Howard, Caldwell \&

115 Ito, 2009). In other words, we could expect larger variations between cultures in the cognitive

116 construct of subjective well-being than in the affective construct. If so, associations between the

117 subjective well-being constructs and psychological well-being might differ between countries as

118 well.

\section{The present study}

120 The study of well-being during adolescence is important since this period of life is characterized

121 by various events and transitions that significantly influence adolescents' well-being (Kjell, 
122 Nima, Sikström \& Garcia, 2013). Moreover, although research on adolescents' well-being has

123 increased in the last decade (e.g., see Garcia \& Siddiqui, 2009a; Garcia \& Siddiqui, 2009b;

124 Garcia \& Sikström, 2013; Fogle, Huebner \& Laughlin, 2002; Funk, Huebner \& Valois, 2006;

125 Sagone \& De Caroli, 2014; De Caroli \& Sagone, 2016), the study of well-being across cultures is

126 still scarce (for a recent review showing that the majority of previous research in this area

127 involves American participants see Proctor, Linley \& Maltby, 2009). The main purposes of this

128 study were (1) to analyze differences in subjective well-being and psychological well-being

129 between Italian and Swedish adolescents and (2) to test if the relationships between the three

130 aspects of subjective well-being (i.e., satisfaction with life, positive affect, and negative affect)

131 and psychological well-being were moderated by the adolescents' nationality.

\section{Method}

\section{Ethical Statement}

134 After consulting with the university's Network for Empowerment and Well-Being's Review

135 Board and according to law (2003: 460, section 2) concerning the ethical research involving

136 humans we arrived at the conclusion that the design of the present study (e.g., all participants'

137 data were anonymous and will not be used for commercial or other non-scientific purposes)

138 required only verbal consent from participants. For the Italian sample, researchers followed the

139 Ethical Code for Italian psychologists (L. 18.02.1989, n.56) and DL for data privacy (DLGS

140 196/2003); Ethical Code for Psychological Research (March 27, 2015) by AIP (Italian

141 Psychologists Association). For the Italian sample also only verbal consent was needed.

\section{Participants}

143 The data was collected at two high schools in the Eastern Sicily, Italy $(N=255,107$ boys and

144148 girls, mean age $=16.19$ years $S D=1.75$ years) and two high schools in the West of Sweden 
$145(N=277,166$ boys and 111 girls, mean age 18.11 years $S D 0.59$ years). The sampling procedure

146 of schools was based on convenience. Teachers and parents were informed about the nature of

147 the study. The school nurse from each school was contacted by the researchers and informed

148 about the study in case any of the students needed counseling. Participants were informed that

149 the study examined how pupils think about their lives in different situations. They were ensured

150 anonymity and informed that participation was voluntary; they had consent from their teachers to

151 participate. The study was conducted in the participants' own classrooms in groups of 20 to 30

152 pupils; the questionnaires were distributed on paper. The entire procedure, including debriefing,

153 took approximately 30 minutes.

154 Measures

155 The Satisfaction With Life Scale (Pavot \& Diener, 2008) assesses the cognitive component of 156 subjective well-being (i.e., life satisfaction) and consists of 5 items (e.g., "In most of my ways

157 my life is close to my ideal") that require a response on a 7-point Likert scale $(1=$ strongly 158 disagree, 7 = strongly agree). Both the Swedish and the Italian versions of this instrument have

159 been previously used in these cultures (e.g., Garcia \& Siddiqui, 2009ab; Fahlgren, Nima, Archer

160 \& Garcia, 2015; Sagone \& De Caroli, 2015). In the current study, this measure had a Cronbach's

$161 \alpha=.85$ in the Italian sample and .93 in the Swedish sample.

162 The Positive Affect and Negative Affect Schedule (Watson, Clark \& Tellegen, 1988)

163 assesses the affective component of subjective well-being by requiring participants to indicate on

164 5-point Likert scale to what extent $(1=$ very slightly, 5 = extremely) they generally experienced

16520 adjectives describing affective states (10 for positive affect and 10 for negative affect) within

166 the last few weeks. The positive affect scale includes adjectives such as "strong", "proud", and

167 "interested"; and the negative affect scale includes adjectives such as "afraid", "ashamed", and 
168 "nervous". The Swedish and Italian versions have been used in previous studies (e.g., Schütz,

169 Archer \& Garcia, 2013; De Caroli \& Sagone, 2016) and demonstrated acceptable internal

170 consistency in the present study: Cronbach's $\alpha$ was .77 for positive affect and .79 for negative

171 affect in the Italian sample and .86 for positive affect and .85 for negative affect in the Swedish 172 sample.

173 Ryff's Scales of Psychological Well-Being - short version (Clarke, Marshall, Ryff and

174 Wheaton, 2001) comprises 18 items with a 6-point Likert $(1=$ strongly disagree, $6=$ strongly

175 agree), 3 items for each of the 6 dimensions: self-acceptance (e.g., "I like most aspects of my

176 personality"), personal growth (e.g., "For me, life has been a continuous process of learning,

177 changing, and growth"), purpose in life ("Some people wander aimlessly through life, but I am

178 not one of them"), environmental mastery (e.g., "I am quite good at managing the responsibilities

179 of my daily life"), autonomy (e.g., "I have confidence in my own opinions, even if they are

180 contrary to the general consensus"), and positive relations with others (e.g., "People would

181 describe me as a giving person, willing to share my time with others"). The Swedish and Italian

182 versions have been used in previous studies (e.g., Garcia, Jimmefors, Mousavi, Adrianson,

183 Rosenberg \& Archer, 2015; De Caroli \& Sagone, 2016). In the present study, we used the whole

184 scale as one general measure of psychological well-being. The Cronbach's $\alpha$ for this

185 psychological well-being composite score were .68 for the Italian sample and .79 for the Swedish 186 sample.

\section{Results}

188 We conducted one Multivariate Analysis of Variance using age as covariate in order to

189 investigate differences between Italian and Swedish adolescents. Specifically, we used country

190 (Italy-Sweden) and gender (male-female) as the independent factors, age as the covariate, and 
191 the different constructs of subjective well-being (satisfaction with life, positive affect, and

192 negative affect) and the psychological well-being composite as the independent variables. We

193 used age as a covariate since the significant difference in age between samples (age mean $_{\text {Italy }}=$

$19416.19 \pm 1.75$, age mean $\left._{\text {Sweden }}=18.11 \pm 0.59\right)$ and the fact that levels of affectivity and

195 psychological well-being fluctuate with age (see Ryff, 1989).

196 Both gender $(F(4,519)=4.84 ; p<.01$, Wilks' Lambda $=.96)$ and country $(F(4,519)=$

$1973.49 ; p<.01$, Wilks' Lambda $=.97$ ) had a significant effect on satisfaction with life and negative 198 affect. Italian adolescents $(M=4.62, S D=1.26)$ scored significantly higher in satisfaction with

199 life $(F(1,522)=6.85 ; p<.01)$ than Swedish adolescents $(M=4.30, S D=1.56)$. Additionally,

200 girls $(M=2.38, S D=.67)$ scored significantly higher in negative affect $(F(1,522)=13.75 ; p<$

$201.001)$ than boys $(M=2.17, S D=.62)$. The interaction of country and gender was no significant

$202(F(4,519)=.76 ; p=.552$, Wilks' Lambda $=.99)$, thus, the difference in life satisfaction between

203 countries was consistent across genders and the difference in negative affect between girls and 204 boys was consistent across countries. No other significant differences were found.

The second analysis was a multiple group Structural Equation modeling to test if the 206 relationship between the three constructs of subjective well-being (i.e., satisfaction with life, positive affect, and negative affect) and psychological well-being was moderated by individuals' nationality. In other words, we used country as the moderator, all three subjective well-being constructs as the independent variables, and psychological well-being as the dependent variable.

210 This model showed a goodness of fit index $=1.00$, a comparative fit index $=1.00$, an incremental

211 fit index $=1.00$, and normed fit index $=1.00$. Thus, indicating that the model is a good-fitting 212 model. 
214 well-being were associated to adolescents' psychological well-being. We tested if the regression

215 weights were significantly different across groups (i.e., both Italian and Swedish adolescents).

216 The result showed that there was a significant difference $\left(C h i^{2}=9.53, p<.05\right)$ on level model

217 between the unconstrained/original model and constrained model (with all constrained regression

218 weights on psychological well-being). In other words, nationality moderated at least one of the

219 paths. In further analyses (path by path), we found that the effect of the relationships between

220 positive affect and psychological well-being $\left(C h i^{2}=1.24, p=.27\right)$ and between negative affect

221 and psychological well-being $\left(C h i^{2}=0.17, p=.68\right)$ were not significantly different between

222 countries. The relationship between life satisfaction and psychological well-being, on the other

223 hand, differed significantly between countries $\left(C h i^{2}=4.12, p<.05\right)$. This relationship was

224 significantly stronger among Swedish adolescents (see Table 2).

225

226

227

228

229

230

231

232

233

234

235

Figure 1 should be about here

Table 1 and 2 should be about here

\section{Discussion}

The purpose of this study was twofold: (1) to analyze differences in subjective well-being and psychological well-being between Italian and Swedish adolescents and (2) to test if the relationships between the three aspects of subjective well-being (i.e., satisfaction with life, positive affect, and negative affect) and psychological well-being were moderated by the adolescents' nationality. At a general level, the results were straightforward: Italian adolescents experience their life as highly satisfying and more close to their ideal than Swedish adolescents, and girls in both countries experience more negative emotions than boys. No significant differences were found with regard to positive emotions or psychological well-being. 
237 supported across the literature. Females usually score higher in characteristics related to negative

238 emotionality, such as, neuroticism, anxiety, depression, rumination, and score lower in

239 dispositional optimism than males (see among others Ellis, 2011; Hyde, Mezulis, \& Abramson,

240 2008; Johnson \& Whisman, 2013; Twenge \& Nolen-Hoeksema, 2002; Bodas \& Ollen- dick,

241 2005; De Bolle, De Fruyt, McCrea, Löckenhoff. Costa, Aguilar-Vafaie, Ahn, Ahn, Alcalay,

242 Allik, Avdeyeva, Bratko, Brunner-Sciarra, Cain, Chan, Chittcharat, Crawford, Fehr, Ficková,

243 Gelfand, Graf, Gülgöz, Hřebíčková, Jussim, Klinkosz, Knežević, Leibovich de Figueroa, Lima,

244 Martin, Marušić, Mastor, Nakazato, Nansubuga, Porrata, Purić, Realo, Reátegui, Rolland,

245 Schmidt, Sekowski, Shakespeare-Finch, Shimonaka, Simonetti, Siuta, Szmigielska, Vanno,

246 Wang, Yik \& Terracciano, 2015; Hopcroft \& McLaughlin, 2012; McCrae, Terracciano, \& 78

247 Members of the Personality Profiles of Cultures Project, 2005; Sagone \& De Caroli, 2016).

248 Interestingly, gender differences in neuroticism, which is almost synonymous with negative

249 affect (Tellegen, 1993), do not reach their full strength until around age 14 (De Bolle, De Fruyt,

250 McCrea, Löckenhoff, Costa, Aguilar-Vafaie, Ahn, Ahn, Alcalay, Allik, Avdeyeva, Bratko,

251 Brunner-Sciarra, Cain, Chan, Chittcharat, Crawford, Fehr, Ficková, Gelfand, Graf, Gülgöz,

252 Hřebíčková, Jussim, Klinkosz, Knežević, Leibovich de Figueroa, Lima, Martin, Marušić,

253 Mastor, Nakazato, Nansubuga, Porrata, Purić, Realo, Reátegui, Rolland, Schmidt, Sekowski,

254 Shakespeare-Finch, Shimonaka, Simonetti, Siuta, Szmigielska, Vanno, Wang, Yik \&

255 Terracciano, 2015); which was the age of the youngest participants in the present study. That

256 being said, although gender differences in negative affect states and traits are present across

257 nations in most studies, these differences seem to depend on which level of gender equity is

258 practiced (Schmitt, Long, McPhearson, O’Brien, Remmert \& Shah, 2016). Although counter- 
259 intuitive, gender differences in negative emotionality are larger in relatively high gender

260 egalitarian cultures (Schmitt, Long, McPhearson, O’Brien, Remmert \& Shah, 2016). Since we

261 did not found any interactions between gender and nationality, our results implicitly suggest that

262 Italy and Sweden might be relatively alike in gender equality. For instance, although Sweden has

263 the fourth place and Italy the fiftieth place in the 2016 report from the World Economic Forum's

264 Global Gender Gap, the mean score of both countries in the area of educational attainment

265 (including the gender equity measured by the Education Indicators by UNESCO) is almost the

266 same (for Sweden 0.999 and for Italy 0.995; see https://www.weforum.org/reports/the-global-

267 gender-gap-report-2016). This is, however, beyond the scope of the present study and we suggest

268 it as an interesting venue for future studies. Additionally, although we state that cultural features,

269 such as, nationality, ethnicity, religious affiliation, and motivation seem to shape how individuals

270 understand "the ideal life" (Tsai, Knutson, and Fung, 2006; Tsai, Miao, and Seppala, 2007;

271 Scollon, Howard, Caldwell \& Ito, 2009; see also George, Ellison \& Larson, 2002; Green \&

272 Elliot, 2009), we do not address, for example, how religious affiliations or "ideal life"

273 constructions relate to our findings. This is definitely another venue for further exploration.

274 We did also found that affectivity (both positive and negative affect) is equally related to

275 psychological well-being across both nations, while life satisfaction was significantly more

276 strongly related to psychological well-being among Swedish adolescents than among Italian

277 adolescents. Firstly, this demonstrated how affectivity and life satisfaction are different

278 constructs of subjective well-being (cf. Diener, 1984) - one addressing an affective part (i.e.,

279 emotions) and the other a cognitive part (i.e., life satisfaction). That is, a person cognitions or

280 self-assessment of biological states, such emotions, and psychological phenomena, such as, life

281 satisfaction. That being said, in order to have a biopsychosocial model of subjective well-being, 
282 we lacked a social component. It is plausible that such a construct is differently associated to

283 psychological well-being among different cultures (cf. Markus \& Kitayama, 1991). Future

284 studies should investigate this further. Harmony, for example, has recently being suggested as a

285 cognitive construct that complements life satisfaction (Kjell, Daukantaite, Hefferon \& Sikström,

286 2016). However, Garcia (2016) goes even further and points out that since harmony is a

287 construct related to the sense of balance and flexibility that an individual experiences in relation

288 to the world or her/his life (cf. Li, 2008ab), harmony is more likely a social component of

289 subjective well-being. Subjective well-being, in turn, is more of a cognitive global construct of

290 well-being, since it is mostly measured through self-reports (see Garcia, 2016, who suggest

291 affect as the cognitive biological part of subjective well-being, life satisfaction as the cognitive

292 psychological part, and harmony as the cognitive social part). Secondly, the differences in

293 associations between life satisfaction and psychological well-being among adolescents from

294 these two countries are in line with the fact that cultural features seem to shape how individuals

295 understand "the ideal life" (Tsai, Knutson, and Fung, 2006; Tsai, Miao, and Seppala, 2007;

296 Scollon, Howard, Caldwell \& Ito, 2009).

297 Limitations and final remarks

298 The cross-sectional and self-report design of the present study limit our conclusions. Also, it is

299 plausible that the difference in age between the two groups could be the factor driving the

300 between-groups difference, rather than nationality. For instance, this could also be the cause of

301 different reliability coefficients for the different measures used here. Additionally, a more valid

302 measure of psychological well-being would allowed us to scrutinize the sub-scales. The different

303 aspects of psychological well-being like self-acceptance, purpose in life and/or positive relations

304 with others might vary between adolescents from Sweden and Italy (cf. Markus \& Kitayama, 
305 1991). That being said, the present study shows that there are larger variations between these two

306 cultures in the cognitive construct of subjective well-being than in the affective construct.

307 Accordingly, associations between the cognitive component, not the affective component, of

308 subjective well-being and psychological well-being differ between countries as well.

\section{References}

310 Archer T, Adolfsson B, Karlsson E. 2008. Affective personality as cognitive-emotional presymptom profiles regulatory for self-reported health predispositions. Neurotoxicity Research 14:21-44 DOI 10.1007/BF03033573

313 Archer T, Adrianson L, Plancak A, Karlsson E. 2007. Influence of affective personality on cognition-mediated emotional processing: Need for empowerment. European Journal of Psychiatry 21:248-262.

316 Biswas-Diener, R., Kashdan, T., \& King, L. A. (2009). Two traditions of happiness research, not two distinct types of happiness. Journal of Positive Psychology, 4, 208-211.

318 Bodas J, Ollendick TH. 2005. Test anxiety: A cross- cultural perspective. Clinical Child and Family Psychology Review 8:65-88.

320 Clarke PJ, Marshall VM, Ryff CD, Wheaton B. 2001. Measuring psychological well-being in the Canadian study of health and aging. International Psychogeriatrics 13:79-90.

322 Cloninger CR. 2004. Feeling good: the science of well-being. New York: Oxford University 323 Press.

324 Cloninger CR, Garcia D. 2015. The heritability and development of positive affect and 325 emotionality. In: Pluess M, ed. Genetics of psychological well-being - the role of heritability and genetics in positive psychology. New York: Oxford University Press, 97113. 
328 De Bolle M, De Fruyt F, McCrae RR, Löckenhoff CE, Costa PT, Jr., Aguilar-Vafaie ME, Ahn 329 CK, Ahn HN, Alcalay L, Allik J, Avdeyeva TV, Bratko D, Brunner-Sciarra M, Cain TR, 330 Chan W, Chittcharat N, Crawford JT, Fehr R, Ficková E, Gelfand MJ, Graf S, Gülgöz S, 331 Hřebíčková M, Jussim L, Klinkosz W, Knežević G, Leibovich de Figueroa N, Lima MP, 332 Martin TA, Marušić I, Mastor KA, Nakazato K, Nansubuga F, Porrata J, Purić D, Realo A, Reátegui N, Rolland JP, Schmidt V, Sekowski A, Shakespeare-Finch J, Shimonaka Y, Simonetti F, Siuta J, Szmigielska B, Vanno V, Wang L, Yik M, Terracciano A. 2015.

De Caroli ME, Sagone E. 2016. Resilience and psychological well-being: differences for affective profiles in Italian middle and late adolescents. Revista INFAD de Psicologia 1:149-160 DOI 10.17060/ijodaep.2016.n1.v1.237

The emergence of sex differences in personality traits in early adolescence: A crosssectional, cross-cultural study. Journal of Personality and Social Psychology 108:171 185.

Dele Fave A. \& Bassi, M. (2009). The contribution of

Delle Fave, A., \& Bassi, M. (2009). The contribution of diversity to happiness research. The Journal of Positive Psychology, 4, 205-207.

Di Fabio A, Bucci O. 2015. Affective profiles in Italian high school students: life satisfaction, psychological well-being, self-esteem, and optimism. Frontiers in Psychology 6:1310 DOI 10.3389/fpsyg.2015.01310

346

Diener E. 1984. Subjective well-being. Psychological Bulletin 95:542-575.

347 Ellis L. 2011a. Identifying and explaining apparent universal sex differences in cognition and 348 behavior. Personality and Individual Differences 51:552-561. 
349 Falhgren E, Nima AA, Archer T, Garcia D. 2015. Person-Centered Osteopathic Practice:

350 Patients' Personality (Body, Mind, and Soul) and Health (Ill-Being and Well-Being).

$351 \quad$ PeerJ 3:e1349 DOI 10.7717/peerj.1349.

352 Fogle LM, Huebner ES, Laughlin JE. 2002. The relationship between temperament and life 353 satisfaction in early adolescence: cognitive and behavioral mediation models. Journal of Happiness Studies 3:373-392 DOI 10.1023/A:1021883830847.

355 Folkman S, Moskowitz JT. 2000. Positive affect and the other side of coping. American 356 Psychologist 55:647-654.

357 Fredrickson BL. 2001. The role of positive emotions in positive psychology: The broaden-and358 build theory of positive emotions. American Psychologist 56:218-226 DOI 10.1037/0003-066X.56.3.218.

360

361

362

363

364

365

366

367

368

369

370

Funk BA III, Huebner ES, Valois RF. 2006. Reliability and validity of a brief life satisfaction scale with a high school sample. Journal of Happiness Studies 7:41-54 DOI 10.1007/s10902-005-0869-7.

Garcia D. 2011. Adolescents' happiness: The role of the affective temperament model on memory and apprehension of events, subjective well-being, and psychological wellbeing. Ph.D. Thesis, University of Gothenburg, Gothenburg.

Garcia D. 2016. A Biopsychosocial Model of Subjective Well-Being: Affectivity, Life Satisfaction, and Harmony. Manuscript in press.

Garcia D, Nima AA, Kjell ONE. 2014. The affective profiles, psychological well-being, and harmony: Environmental mastery and self-acceptance predict the sense of a harmonious life. PeerJ 2:e259 DOI 10.7717/peerj.259 
371 Garcia D, Archer T. 2012. Adolescent life satisfaction and well-being. Journal of Alternative $372 \quad$ Medicine Research 4:271-279.

373 Garcia D, Jimmefors A, Mousavi F, Adrianson L, Rosenberg P, Archer T. 2015. Self-regulatory

374

375

376

377

378

379

380

381

382

383

384

385

386

387

Mode (Locomotion and Assessment), Well-Being (Subjective and Psychological), and exercise behavior (Frequency and Intensity) in Relation to High School Pupils' Academic Achievement. PeerJ 3:e847 DOI 10.7717/peerj.847

Garcia D, Siddiqui A. 2009a. Adolescents’ psychological well-being and memory for life events: influences on life satisfaction with respect to temperamental dispositions. Journal of Happiness Studies 10:387-503

Garcia D, Siddiqui A. 2009b. Adolescents' affective temperaments: life satisfaction, interpretation, and memory of events. The Journal of Positive Psychology 4:155-167.

Garcia D, Sikström S. 2013. Quantifying the semantic representations in adolescents' memories of positive and negative life events. Journal of Happiness Studies 14:1309-1323 DOI $10.1007 / \mathrm{s} 10902-012-9385-8$.

George LK, Ellison CG, Larson DB. 2002. Explaning the relationships between religious involvement and health. Psychological Inquiry 13:190-200.

Green M, Elliott M. 2009. Religion, Health, and Psychological Well-Being. Journal of Religion and Health 49:149-163

Hopcroft RL, McLaughlin J. 2012. Why is the sex gap in feelings of depression wider in high gender equity countries? The effect of children on the psychological well-being of men and women. Social Science Research 41:501-513. 
392 Huebner ES, Dew T. 1996. The interrelationships of positive affect, negative affect, and life

393

394

395

396

397

398

399

400

401

402

403

404

405

406

407

408

409

410

411

412

413

414

satisfaction in an adolescent sample. Social Indicators Research 38:129-137 DOI 10.1007/BF00300455.

Hyde JS, Mezulis AH, Abramson LY. 2008. The ABCs of depression: Integrating affective, biological, and cognitive models to explain the emergence of the gender dif- ference in depression. Psychological Review 115:291 - 313.

Johnson DP, Whisman MA. 2013. Gender differences in rumination: A meta-analysis. Personality and Individual Differences 55:367-374.

Kashdan, TB, Biswas-Diener R, King LA. 2008. Reconsidering happiness: The costs of distinguishing between hedonics and eudaimonia. The Journal of Positive Psychology, 3, $219-233$.

Kjell ONE, Daukantaité D, Hefferon D, Sikström S. 2016. The Harmony in Life Scale Complements the Satisfaction with Life Scale: Expanding the Conceptualization of the Cognitive Component of Subjective Well-Being. Social Indicators Research 126:893919. DOI: 10.1007/s11205-015-0903-z.

Kjell ONE, Nima AA, Sikström S, Archer T, Garcia D. 2013. Iranian and Swedish adolescents: differences in personality traits and well-being. PeerJ 1:e197; DOI 10.7717/peerj.197.

Kobasa SC, Maddi SR, Kahn S. 1982. Hardiness and health: a prospective study. Journal of Personality and Social Psychology 42:168-177 DOI 10.1037/0022-3514.42.1.168.

Li C. 2008a. The ideal of harmony in ancient Chinese and Greek philosophy. Dao 7:81-98.

Li C. 2008b. The philosophy of harmony in classical confucianism. Philosophy Compass 3:13.

Markus HR, Kitayama S. 1991. Culture and the self: Implications for cognition, emotion, and motivation. Psychological Review 98:224-253. DOI:10.1037/0033-295X.98.2.224. 
415 Masten AS, Hubbard JJ, Gest SD, Tellegen A, Garmezy N, Ramirez M. 1999. Competence in the 416 context of adversity: pathways to resilience and maladaptation from childhood to late adolescence. Development and Psychopathology 11:143-169.

418 McCrae RR, Terracciano A, \& 78 Members of the Personality Profiles of Cultures Project.2005.

419 Universal features of personality traits from the observer's perspective: Data from 50 $420 \quad$ cultures. Journal of Personality and Social Psychology 88:547-561.

421 Norlander T, Johansson A, Bood SA. 2005. The affective personality: its relation to quality of 422 sleep, well-being and stress. Social Behavior and Personality 33:709-722

423 Pallant JF, Lae L. 2002. Sense of coherence, well-being, coping and personality factors: Further 424 425 evaluation of the sense of coherence scale. Personality and Individual Differences 33:3948

426

Pavot W, Diener E. 2008. The Satisfaction With Life Scale and the emerging construct of life 428 satisfaction. The Journal of Positive Psychology 3:137-152 DOI $10.1080 / 17439760701756946$

Proctor CL, Linley A, Maltby J. 2009. Youth life satisfaction: a review of the literature. Journal 430 of Happiness Studies 10:583-630 DOI 10.1007/s10902-008-9110-9.

431 Ryan, RM, Huta V. 2009. Wellness as healthy functioning or wellness as happiness: The 432 importance of eudaimonic thinking. The Journal of Positive Psychology: Dedicated to furthering research and promoting good practice, 4, 202-204.

434 Ryan RM, Frederick CM. 1997. On energy, personality and health: Subjective vitality as a 435 dynamic reflection of well-being. Journal of Personality 65:529-565 DOI 436 10.1111/j.1467-6494.1997.tb00326.x 
437 Ryff CD, Keyes C. 1995. The structure of psychological well-being revisited. Journal of $438 \quad$ Personality and Social Psychology 69:719-727.

439 Ryff CD, Singer B. 1998. The contours of positive human health. Psychological Inquiry 9:1-28.

440 Ryff CD, Singer B. 2003. Flourishing under fire: Resilience as a prototype of challenged 441 thriving. In: Keyes CLM, \& Haidt J. eds. Flourishing: Positive psychology and the life well-lived. Washington, DC: American Psychological Association, 15-36. http://dx.doi.org/10.1037/10594-001

444

446

447

448

449

450

451

452

453

454

455

456

457

458

459

well-being. Journal of Personality and Social Psychology 57:1069-1081 http://dx.doi.org/10.1037/0022-3514.57.6.1069

Ryff CD. 2013. Psychological Well-being revisited: Advances in the Science and Practice of Eudaimonia. Psychotherapy and Psychosomatics 83:10-28 DOI 10.1159/000353263

Sagone E, De Caroli ME. 2014. Relationships between psychological well-being and resilience in middle and late adolescents. Procedia - Social and Behavioral Sciences, 141:881-887 DOI 10.1016/j.sbspro.2014.05.154

Sagone E, De Caroli ME. 2015. Positive Personality as a Predictor of High Resilience in Adolescence. Journal of Psychology and Behavioral Science 3:45-53 DOI 10.15640/jpbs.v3n2a6.

Sagone E, De Caroli ME. 2016. Are value priorities related to dispositional optimism and resilience? A correlational study. Contemporary Educational Researches Journal 6:11-20

Scheier MF, Carver CS, Bridges MW. 2001. Optimism, pessimism, and psychological wellbeing. In: Chang EC. ed., Optimism and pessimism: Implications for theory, research, and practice. Washington, DC: American Psychological Association, 189-216. 
460 Schimmack U, Diener E, Oishi S. 2002. Life-satisfaction is a momentary judgement and a stable 461 personality characteristic: the use of chronically accessible and stable sources. Journal of 462 Personality 70:345-384 DOI 10.1111/1467-6494.05008.

463 Schmitt DP, Long AE, McPhearson A, O’Brien K, Remmert B, Shah SH. 2016. Personality and 464 gender differences in global perspective. International Journal of Psychology. DOI: 10.1002/ijop. 12265.

Schütz E, Archer T, Garcia D. 2013. Character Profiles and Adolescents' Self-reported Affect. Personality and Individual Differences 54:841-844 DOI 10.1016/j.paid.2012.12.020.

468

469

470

471

472

473

474

475

476

477

478

479 480

481

482

Scollon CN, Howard AH, Caldwell AE, Ito S. 2009. The role of ideal affect in the experience and memory of emotions. Journal of Happiness Studies 10:257-269 DOI: 10.1007/s10902-007-9079-9

Seligman MEP, Csikszentmihalyi M. 2014. Positive Psychology: An Introduction. In: Csikszentmihalyi M. ed. Flow and the Foundations of Positive Psychology. Springer Netherlands, 279-298. DOI 10.1007/978-94-017-9088-8_18

Seligman MEP. 2002. Authentic Happiness: Using the New Positive Psychology to Realize Your Potential for Lasting Fulfillment. New York, NY: Free Press.

Straume LV, Vittersø J. 2012. Happiness, inspiration and the fully functioning person: Separating hedonic and eudaimonic well-being in the workplace. The Journal of Positive Psychology: Dedicated to furthering research and promoting good practice, 7, 387-398.

Tellegen A. 1993. Folk concepts and psychological concepts of personality and personality disorder. Psychological Inquiry 4:122-13.

Tsai JL, Knutson B, Fung HH. 2006. Cultural variation in affect valuation. Personality processes and Individual Differences 90:288-307 DOI 10.1037/0022-3514.90.2.288 
483 Tsai JL, Miao FF, Seppala E. 2007. Good feelings in Christianity and Buddhism: Religious 484 differences in ideal affect. Personality and Social Psychology Bulletin 33:409-421 DOI 485 $10.1177 / 0146167206296107$.

486

487

488

489

490

491

492

493

494

495

496

497

498

499

500

501

502

503

504

505

Twenge JM, Nolen-Hoeksema S. 2002. Age, gender, race, socioeconomic status, and birth cohort difference on the children's depression inventory: A meta-analysis. Journal of Abnormal Psychology 111:578-588.

Waterman AS. 2008. Reconsidering happiness: A eudaimonist's perspective. The Journal of Positive Psychology: Dedicated to furthering research and promoting good practice, 3, $234-252$.

Watson D, Clark LA, Tellegen A. 1988. Development and validation of brief measures of positive and negative affect: the PANAS scales. Journal of Personality and Social Psychology 54:1063-1070.

\section{Legends}

Figure 1. Structural equation modelling showing all correlations for (A) Italian $(N=255)$ and (B) Swedish adolescents' $(N=275)$ subjective well-being and psychological well-being, along the standardized parameter estimates.

03 Table 1. Results of the structural equation model using all three subjective well-being constructs as the predictors of (A) Italian $(N=255)$ and (B) Swedish adolescents' $(N=275)$ psychological well-being. 
507 Table 2. Results of the compare nested models using Chi-square difference test. 508 